\title{
Resuscitative Endovascular Balloon Occlusion of the Aorta Consensus: The Panamerican Experience
}

\author{
${ }^{1}$ Michael W Parra, ${ }^{2}$ Megan L Brenner, ${ }^{3}$ Todd E Rasmussen, ${ }^{4}$ Claudia Orlas, ${ }^{5}$ Joao B Rezende-Neto, ${ }^{6}$ Thomas M Scalea, \\ ${ }^{7}$ Carlos A Ordonez
}

\section{RESUMEN}

El Balón de Resucitación Endovascular de Aorta (REBOA) es una herramienta dentro de la indumentaria del cirujano de trauma utilizada para obtener control de forma endovascular de la hemorragia mientras asegura la redistribución del flujo sanguíneo a órganos centrales como corazón y cerebro. Su uso en múltiples escenarios de trauma y no-trauma ha venido creciendo en la última década, sin embargo hay aspectos dentro de las indicaciones, técnica de colocación y complicaciones que continúan siendo controversiales. Actualmente no hay un consenso entre los cirujanos de trauma de las Américas sobre la implementación de esta herramienta para la reanimación y control de la hemorragia.

La Sociedad Panamericana de Trauma (PTS) en conjunto con la Asociación Colombiana de Cirugía (ACC) realizaron en 2018 el XXXI Congreso Panamericano de Trauma, Cuidado Crítico y Cirugía de Emergencias (Agosto 14 al 17) en Cartagena, Colombia. Uno de los objetivos del congreso fue crear un consenso de manejo en trauma a cargo de cirujanos de trauma expertos de todas las Américas (Norte, Centro, Suramérica y el Caribe). Este es el primer consenso que aborda las indicaciones, técnica de uso y complicaciones del REBOA en las Américas.

\footnotetext{
${ }^{1,7}$ Surgeon, ${ }^{2}$ Director and Surgeon, ${ }^{3}$ Professor, Dean, and Surgeon, ${ }^{4}$ Physician, ${ }^{5}$ Associate Professor and Surgeon, ${ }^{6}$ Professor and Chief

${ }^{1}$ Department of Trauma and Acute Care Surgery, Broward Health Imperial Point, Broward Health North, Broward Health Medical Center, Fort Lauderdale, Florida, USA

${ }^{2}$ Department of Comparative Effectiveness and Clinical Outcomes Research Center (CECORC), University of California Riverside School of Medicine, Moreno Valley, California, USA

${ }^{3}$ Department of F. Edward Hebert School of Medicine, Bethesda, Maryland, USA

${ }^{4,7}$ Department of Trauma and Acute Care Surgery, Fundación, Valle del Lili, Universidad del Valle, Cali, Valle del Cauca, Colombia

${ }^{5}$ Department of Trauma and Acute Care General Surgery, Toronto, Ontario, Canada

${ }^{6}$ Department of Trauma and Acute Care Surgery, R Adams Cowley Shock Trauma Center, Baltimore, Maryland, USA

Corresponding Author: Carlos A Ordonez, Surgeon, Department of Trauma and Acute Care Surgery, Fundación Valle del Lili, Universidad del Valle, Cali, Valle del Cauca, Colombia, e-mail: ordonezcarlosa@gmail.com
}

Palabras clave: Consenso, Control de daños, Control de la hemorragia, Procedimientos endovasculares, Resuscitative Endovascular Balloon Occlusion of the Aorta, Trauma.

\section{ABSTRACT}

Resuscitative endovascular balloon occlusion of the aorta (REBOA) is a tool of trauma surgeons used to obtain endovascular control of hemorrhage while ensuring the redistribution of blood flow to central organs such as the heart and brain. Its use in multiple trauma and non-trauma scenarios has been growing in the last decade; however, there are aspects within the indications, deployment technique and complications that continue to be controversial. Currently, there is no consensus among trauma surgeons in the Americas regarding the implementation of this tool for resuscitation and hemorrhage control.

The Panamerican Trauma Society (PTS) in conjunction with the Colombian Association of Surgery recently convened 2018, XXXI Panamerican trauma, critical care, and emergency surgery Congress (August 14th to 17th) in Cartagena, Colombia. One main objective of the Congress was to create a consensus in trauma management via expert opinions of leading surgeons from North, Central and South America and the Caribbean. It is the first consensus that addresses the indications, deployment technique and complications of REBOA in the Americas.

Keywords: Consensus, Damage control, Endovascular procedures, Hemorrhage control, Resuscitative endovascular balloon occlusion of the aorta, Trauma.

How to cite this article: Parra MW, Brenner ML, Rasmussen TE, Orlas C, Rezende-Neto JB, Scalea TM, Ordonez CA. Resuscitative Endovascular Balloon Occlusion of the Aorta Consensus: The Panamerican Experience. Panam J Trauma Crit Care Emerg Surg 2018;7(3):171-182.

Source of support: Nil

Conflict of interest: None

\section{BACKGROUND}

Hemorrhagic shock is the leading cause of death in trauma patients worldwide. Control of bleeding, maintenance of tissue oxygenation, correction of coagulopathy, and prevention of hypothermia remain therapeutic mainstays for critically injured patients with hemorrhagic shock. ${ }^{1}$ Traumatic hemorrhage is classified into two types: compressible and non-compressible, with the former being easier to control and carries less risk of death. ${ }^{2}$

Non-compressible hemorrhage of the torso (NCTH) is classified according to anatomical site: (a) Pulmonary 
injury (massive haemothorax, pulmonary vascular injury); (b) Solid organ injury: grade IV (Liver, Kidney, Spleen); (c) Named axial torso vessel; (d) Pelvic fracture with ring disruption. ${ }^{2,3}$ Temporary occlusion of the aorta as a surgical technique to increase both proximal and central perfusion to vital organs such as the heart and brain in the setting of shock is not new. ${ }^{4}$ REBOA was reported as early as the Korean War and has been described since then in multiple recent publications. ${ }^{5-7}$ Despite the growing evidence of endovascular technologies for the management of trauma, established guidelines for their appropriate use are limited and/or non-existent. ${ }^{8}$ In Latin-America, the use or REBOA in trauma patients has been reported in combination with a median sternotomy in hemodynamically unstable patients with supra-diaphragmatic penetrating trauma, and also its use outside the realm of trauma in obstetric patients with abnormal placentation and hemorrhagic shock., ${ }^{9,10}$ These findings suggest that the clinical application of a REBOA can be feasible for low to middle-income countries if used following proper training and guidelines. Our goal is to create a consensus document on the clinical applications of a REBOA based on existing evidence regarding its indications, implementation and the potential complications associated with its use.

\section{METHODS}

The Panamerican Trauma Society (PTS) in conjunction with the Colombian Association of Surgery recently convened 2018, XXXI Panamerican Trauma, Critical Care and Emergency Surgery Congress (August 14th to
Surgeons from North, Central and South America and the Caribbean. Before writing the REBOA consensus, a stepwise analysis approach was taken which included a comprehensive review of the literature. Information pertaining to techniques, indications, contraindications, and complications were taken into final consideration.

\section{DISCUSSION}

\section{Indications for REBOA in the Americas}

Currently, the indications for the use of REBOA are controversial and not universal as can be seen in Figures $1 \mathrm{~A}$ and $\mathrm{B}$ which depict different clinical algorithms among trauma centers in the Americas. We all agree that the primary maneuver to obtain hemorrhage control is determined based on the patient's condition, mechanism of injury and the likely primary anatomical site of hemorrhage, which is determined by clinical assessment, focused abdominal sonographic examination for trauma (FAST), chest X-ray (CXR), and pelvic X-ray. ${ }^{11}$

Following these principles we have reached consensus on the use of REBOA for the following case-specific scenarios for severe injury and shock:

\section{Patients in Traumatic Arrest}

- Patients who arrive at the emergency department(ED)/ trauma center with cardiopulmonary resuscitation $(\mathrm{CPR})$ in progress can undergo resuscitative thoracotomy (RT) in the ED, as long as the duration of the CPR does not exceed 15 minutes for penetrating thoracic trauma, 10 minutes for blunt trauma, or

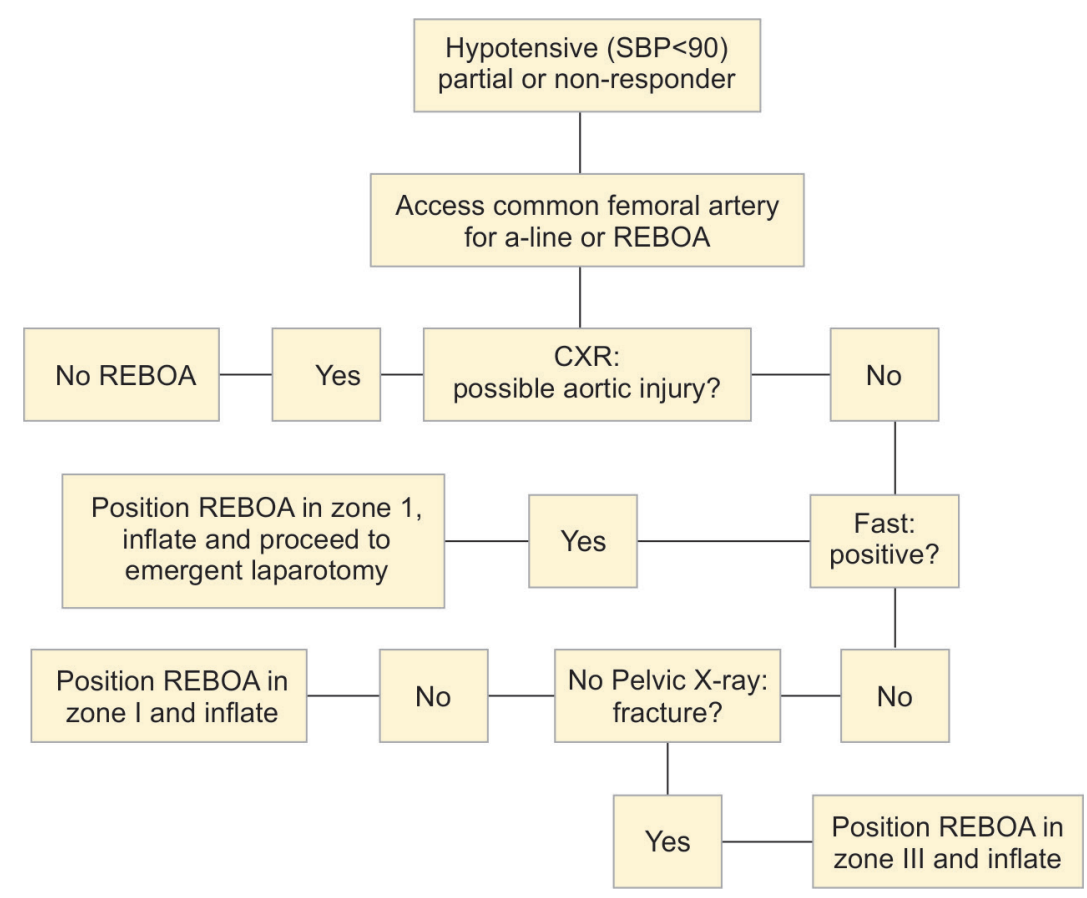

Fig. 1A: The algorithm for trauma management with REBOA created by members from the Division of Trauma and Critical Care at the R Adams Cowley Shock Trauma Center 


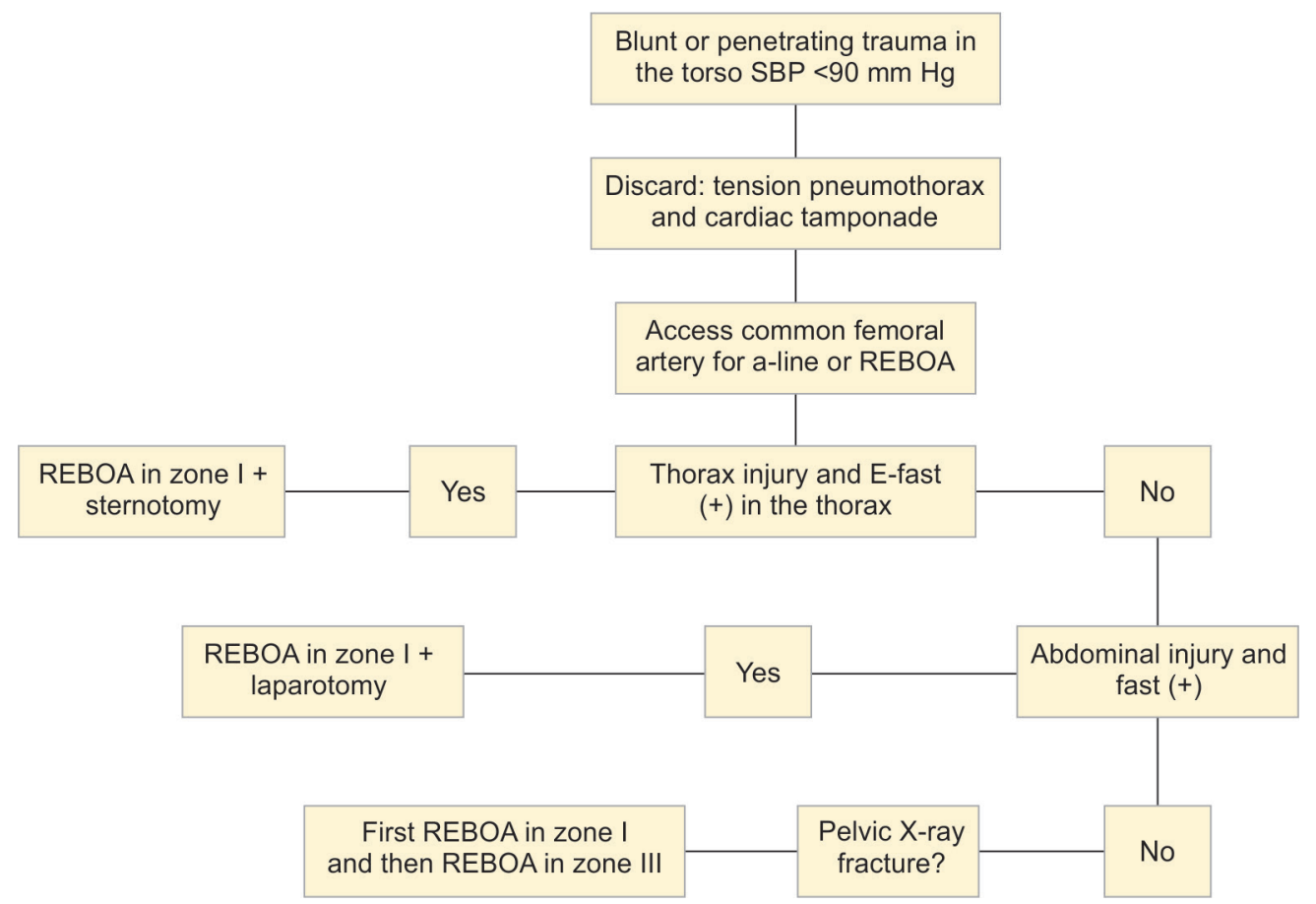

Fig. 1B: The algorithm for trauma management with REBOA created by members from two trauma centers in Latinamerica (Fundación Valle del Lili - Hospital Universitario del Valle)

5 minutes for non-torso penetrating trauma. ${ }^{12}$ The decision to perform RT in situations of prolonged CPR is physician-dependent.

- Patients in arrest from penetrating or blunt mechanisms can undergo REBOA placement in zone I with CPR in progress if FAST and eFAST exams are negative for intra-abdominal hemorrhage, pericardial tamponade, massive hemothorax and/ or tension pneumothoraces. ${ }^{13}$ Data from a high volume US REBOA center shows increased $\mathrm{EtCO}_{2}$ after REBOA, as well as increased survival out of the ED, compared to patients who receive RT for the same indication. Total cardiac compression fraction is also higher in REBOA patients as CPR can continue throughout the procedure, whereas there is significant time during RT when the heart is without active cardiac massage. ${ }^{14,15}$ Earlier data from the same center demonstrates that open cardiac massage is equally effective as closed chest compressions as measured by $\mathrm{EtCO}_{2} \cdot{ }^{16}$

\section{Thoracic Hemorrhage}

- The REBOA is indicated for traumatic life-threatening hemorrhage below the diaphragm in patients in hemorrhagic shock who are unresponsive or transiently responsive to resuscitation. ${ }^{17}$

- Patients in hemorrhagic shock after penetrating thoracic trauma will generally require emergent RT. One exception is the patient with thoracoabdominal trajectory. In this case, rapid determination of the cavity with predominant blood loss (abdominal vs. thoracic) and exclusion of pericardial blood using CXR and FAST guides ones attention to the correct body cavity in the correct order. ${ }^{18}$

- The patient in extremis after penetrating thoracic injury, that is, SBP less than $60 \mathrm{~mm} \mathrm{Hg}$, should have prompt RT in the ED because cardiovascular collapse is imminent. In this scenario, intra-thoracic hemorrhage can be directly controlled, and the descending thoracic aorta can be occluded above the diaphragm to redistribute blood flow to the myocardium and the brain. The deployment of REBOA in the setting of thoracic hemorrhage is not appropriate and potentially dangerous because it could exacerbate hemorrhage from thoracic great vessels. ${ }^{11}$

- The most recent guideline by the United States Army Joint Trauma System establishes that "shock or arrest secondary to penetrating chest trauma is a relative contraindication to $\mathrm{REBOA}^{\prime \prime}$ and thus, trauma surgeons had been reluctant and have been advised against deploying REBOA in these scenarios because a left anterolateral thoracotomy can be both diagnostic and therapeutic, while REBOA could worsen proximal hemorrhage if the aorta is occluded below the level of injury in a closed thorax. ${ }^{19}$

- Intra-thoracic injuries with active bleeding results in a concomitant decrease in systemic blood pressure and blood flow. In these scenarios, the deployment of a REBOA in zone I of the aorta produces blood volume redistribution which in turn causes a rise in both blood pressure and blood flow through the vascular system above the point of occlusion. ${ }^{20-22}$ 
- Although this phenomenon also occurs at the wound site and theoretically the bleeding rate through the wound could potentially increase, there are case reports to suggest that despite the possible increased risk of potentially increasing the rate of bleeding from the injury site from the placement of a REBOA in zone I, REBOA can effectively restore proximal blood flow to essential organs (brain and heart) and simultaneously provide crucial time for the treating trauma surgeon to access and control the source of hemorrhage. ${ }^{10}$

Recent South American experience suggests that the deployment of a REBOA in conjunction with an appropriate open surgical approach for complex thorax injuries may be feasible. ${ }^{10}$ The deployment of REBOA in patients with isolated penetrating intra-thoracic injuries remains controversial. We propose that a median sternotomy be performed in conjunction with REBOA as a feasible and effective means of hemorrhage control in patients suffering from penetrating chest trauma who present hemodynamically unstable. The objective of our study was to present our initial experience with this approach.

\section{MATERIALS AND METHODS}

A prospectively collected case series of the use of REBOA $^{10}$ Fr. The benefit of "vital flow" outweighs the risk of increase hemorrhage from the injury site, as it allows for better myocardial and cerebral perfusion in a patient with shock and at risk for hemodynamic collapse. The trauma surgeon may deploy a Foley catheter/finger or any other temporary packing device or maneuver via the actively bleeding site to ameliorate the blood loss while appropriate definitive surgical hemorrhage control is being achieved. Using REBOA for resuscitation in the setting of open thoracic surgical repair for resuscitation is an option if cross-clamping the aorta is not available or possible. Using REBOA in the setting of minor thoracic bleeding in a patient who is exsanguinating from abdominal or pelvic hemorrhage is also feasible, as long as the thoracic hemorrhage is controlled or stops after the main source of hemorrhage is controlled, OR vigilant monitoring occurs to ensure the thoracic injury does not worsen with REBOA.

\section{Abdominal Hemorrhage}

- Abdominal trauma with hemorrhagic shock is a clear indication for emergent laparotomy. In the patient in extremis, RT with descending thoracic aortic occlusion limits subdiaphragmatic hemorrhage before laparotomy and direct hemorrhage control. An unanswered question is whether REBOA can be deployed as safely and as rapidly as RT. Data from the US suggests there is no difference in time to $\mathrm{AO}$ with $\mathrm{RT}$ and $\mathrm{REBOA}^{23}$ intervention, and outcome variables were collected and analyzed to compare REBOA and open $\mathrm{AO}$.

\section{RESULTS}

From November 2013 to February 2015, 114 AO patients were captured (REBOA, 46 open AO, 68. Furthermore, if arterial access is obtained, time to $\mathrm{AO}$ is significantly faster with REBOA than $\mathrm{RT}^{24}$ both including and excluding time required for common femoral artery (CFA expertise and experience with the procedures may favor RT over REBOA for this indication. ${ }^{11}$

- In a recent meta-analysis from latin american (LATAM) compared REBOA to RT in patients with non-compressible torso hemorrhage evaluated their outcomes and mortality. A total of 1276 patients were included and the initial analysis found that although lower in REBOA patients, the odds of mortality did not significantly differ between the two groups ${ }^{25}$.

- The balloon catheter may be inflated at the level of the distal thoracic aorta (zone 1) for control of severe intra-abdominal or retroperitoneal hemorrhage, or those with traumatic arrest from hemorrhage in any location below the diaphragm. ${ }^{17}$

\section{Pelvic Hemorrhage}

- Patients with exsanguinating hemorrhage from pelvic fractures have continued to present complex challenges to trauma surgeons. Despite algorithms streamlining multidisciplinary care, mortality has remained high. ${ }^{26}$ The balloon catheter may be inflated at the distal abdominal aorta (Zone 3) for patients with severe pelvic, junctional, or proximal lower extremity hemorrhage. ${ }^{17}$ Patients who are in arrest from a pelvic or lower hemorrhage should receive REBOA at zone 1 as a resuscitative measure, with temporary hemorrhage control as a secondary benefit.

- The REBOA is a safe and effective tool in improving the hemodynamics after severe pelvic trauma and life-threatening hemorrhage. ${ }^{22}$ Pelvic packing can be successful in limiting transfusion requirements and the need for angioembolization ${ }^{27}$ facilitates emergent operative procedures, and ensures efficient use of angioembolization (AE transfer of patients to the interventional radiology suite for angioembolization is only appropriate when other sources of major hemorrhage have been excluded. Additionally, transfer of patients with REBOA to a hybrid operating suite can provide the opportunity for open and catheter-based treatment of the injury. It seems 
that REBOA deployed in zone III is an option for immediate hemorrhage control in the patient with pelvic fractures in hemorrhagic shock. ${ }^{28}$

\section{Pregnant Woman with Abnormal Placentation and Other Forms of Non-traumatic Hemorrhage}

- In recent years, endovascular management in the form of intravascular balloon occlusion catheters has grown to be part of the surgical plan to control massive maternal hemorrhage..$^{25,29,30-33}$

- In a systematic review and meta-analysis that included a total of 441 patients, the quantitative analysis found that the use of REBOA as prophylaxis for the prevention of major maternal hemorrhage was associated with a lower amount of intraoperative blood loss (mean difference: $-1,384.66 \mathrm{~mm}$; $95 \%$ confidence interval, $-2,141.74$ to -627.58 ) and lower requirements of blood products transfused (mean difference, -2.42 units; $95 \%$ confidence interval, -3.90 to -0.94$){ }^{25}$

- Trauma and acute care surgeons with training can deploy REBOA at the bedside of an ED resuscitation area, ICU, and/or in a conventional operating room. An implication of this could be the possibility of making this kind of procedure accessible to austere environments where severe hemorrhage continues to be the leading cause of maternal death. ${ }^{34}$ Further, the significance of the trauma and acute care surgeon goes beyond the deployment of REBOA. Because the surgical team must be prepared in all cases to manage massive hemorrhage, their background and operative skills can, at some point, be fundamental in the surgical rescue of patients with abnormal placentation with ongoing life-threatening bleeding as part of a multidisciplinary team. ${ }^{25}$

- Many case reports have been published over the past few decades of REBOA use for non-traumatic hemorrhage. Now with this skillset in the hands of acute care surgeons who are available in the hospital 24 hours per day, the indications for use are broadening and an increase in use is occurring. ${ }^{35,36}$

\section{Complications of REBOA}

Despite the possible benefits of REBOA, serious complications related to groin access have been reported, and there is a paucity of evidence about the safety associated with its insertion and deployment. ${ }^{1,9}$ Reported femoral access complications include arterial disruption, dissection, pseudoaneurysms, hematoma, thromboemboli, extremity isquemia, and extremity loss. ${ }^{8,37}$ The incidence of such complications in a recent meta-analysis was found to be about four to five percent based on the results of 13 studies published worldwide. The most common were thrombotic and/or embolic complications, with or without signs of distal ischemia. Other complications included femoral pseudoaneurysms, femoral artery dissection and femoral artery injury requiring amputation in $2.1 \%$ of cases. ${ }^{38}$ Less severe arterial access injuries can be treated with primary patch repair, stent-grafting, or arterial reconstruction. Extremity complications in the setting of REBOA used in patients with severe vascular, bony, or soft tissue injury are complex and multi-factorial, ${ }^{39}$ and our understanding of the role REBOA plays in these complications are actively evolving. Systemic complications of REBOA including renal dysfunction, paralysis, coagulopathy, mesenteric ischemia, and reperfusion injury are actively under investigation.

\section{REBOA Technique}

The original technique published by Stannard et al. ${ }^{40}$ has been modified and is now taught in several global endovascular trauma management courses. ${ }^{41,42}$ The steps include arterial access, balloon positioning, balloon inflation, management during balloon occlusion, balloon deflation, and sheath removal. Additionally, we have integrated the technical recommendations previously established by trauma and acute care surgeons with extensive clinical experience in catheter-based techniques including REBOA. ${ }^{8}$

- Step 1-Arterial Access: Establishing arterial access is the first step in performing REBOA and it is often the most technically challenging step. Hemorrhagic shock, vasospasm, and catecholamine surge can narrow blood vessels, making them more difficult to locate and cannulate. In addition, hypothermia, acidosis, coagulopathy, platelet dysfunction, and hyperfibrinolysis may increase the risk of bleeding from the access site. Ideally, arterial access for REBOA is obtained via. the common femoral artery (CFA) overlying the femoral head below the inguinal ligament. This location allows cannulation in a larger diameter artery, which carries less risk of arterial thrombosis than cannulation of the superficial femoral artery (SFA).

Conversely, accidental proximal puncture of the external iliac artery can lead to uncontrolled, noncompressible retroperitoneal hemorrhage during and/or after the intervention. One strategy to improve successful arterial cannulation in the ER/Trauma Bay setting includes ultrasound guidance to enhance identification of the CFA. ${ }^{43}$ An alternative method is to expose the artery by open cut-down, especially for patients in extremis. Some experts recommend first accessing the artery with a $4 \mathrm{Fr}$ to $5 \mathrm{Fr}$ micropuncture catheter. Advocates of this approach suggest that the smaller sheath can be used proactively in patients who may deteriorate, allowing for 
arterial blood pressure monitoring and collection of blood samples, as well as confirming the need for REBOA before committing to larger sheath placement.

Obtaining arterial access prior to intubation or induction of anesthesia may be warranted in order to have arterial monitoring and potential REBOA access prior to potential hemodynamic collapse that can occur after the administration of paralytics or anesthetic agents. ${ }^{44,45}$ Similarly, arterial access may be desired prior to transporting transient responders to the computed tomography scanner or intensive care unit in the event REBOA becomes necessary. In other cases, REBOA can be performed before the CT scan in cases where the disposition is undecided, particularly in the event of severe multi-trauma with non-survivable traumatic brain injury. ${ }^{46}$

- Step 2-Balloon Positioning: The two anatomical locations described for REBOA are zone 1 (distal to left subclavian origin; proximal to the celiac axis) and zone 3 (distal to renal arteries; proximal to aortic bifurcation). Zone 1 occlusion has a greater risk of organ ischemia, with few patients surviving complete occlusion times longer than an hour. ${ }^{1,47}$ R. Adams Cowley Shock Trauma Center, Baltimore, Maryland, and Herman Memorial Hospital, The Texas Trauma Institute, Houston, Texas.

\section{RESULTS}

REBOA was performed by trauma and acute care surgeons for blunt $(n=4$. On the other hand, zone 3 occlusions may have a longer tolerable occlusion time, but does not control any hemorrhage above this level, and provides less support to myocardial and cerebral perfusion. ${ }^{48}$

Malposition of the balloon can be even more catastrophic. Inflation of the balloon catheter within the aortic arch or heart (zone 0 ) has the potential to induce myocardial damage directly, by creating excessive ventricular afterload, or by direct occlusion of the vessels providing cerebral blood flow. ${ }^{49}$ Inflation in the visceral segment of the aorta (zone 2) can increase blood flow through the celiac axis, worsening upper abdominal hemorrhage while inducing renal ischemia. Current REBOA guidelines suggest that balloon placement be dictated by the injury pattern (e.g., zone 3 placement for isolated pelvic injuries and zone 1 placement for solid organ and/or abdominal vascular injuries resulting in a positive focused assessment with sonography for trauma (FAST) examination. ${ }^{28,50,51}$ It has been our experience at a level 1 Trauma center in South America that patients who present to our institution hemodynamically unstable with severe pelvic fractures benefit enormously from the placement and balloon inflation of the REBOA initially in zone 1 with the goal of maximizing the initial benefits of a damage control resuscitation with the endpoints of optimizing as quickly as possible targeted vital organ perfusion which include the brain and the heart and then and only then we deflate the balloon and re-inflate it in zone 3 for proximal selective hemorrhage control of the pelvis. As previously mentioned, this is a current strategy for patients in arrest from pelvic hemorrhage as REBOA is used primarily as a resuscitative tool. Our experience differs from other approaches for dealing with these injuries, where it is recommended to place the balloon in zone 3 first (Fig. 2). Clinical series have demonstrated improvement in hemodynamics with zone 3 REBOA for unstable patients with pelvic fractures. ${ }^{13,52} \mathrm{~A}$ recent animal study compared the hemodynamic effects of REBOA in zone 1 vs. zone 3 and found that during the intervention, the mean arterial pressure was significantly higher in zone 1 animals when compared to zone 3 animals $(127.9 \pm 1.3$ vs. $53.4 \pm 1.1 \mathrm{~mm} \mathrm{Hg} ; \mathrm{p}<0.01)$, and both were higher than control animals/non-REBOA $(42.9 \pm 0.9 \mathrm{~mm}$ $\mathrm{Hg}) .^{53}$ The benefit of this dramatic increase in proximal perfusion with zone 1 occlusion does come at the cost of a greater distal ischemic burden that was not seen in animals receiving Zone 3 REBOA. In addition to the ischemia-reperfusion injury suffered by the subjects upon reperfusion following complete aortic occlusion, current reports suggest a significant physiologic burden inflicted by the extremely high cardiac afterload and proximal blood pressures during zone 1 occlusion. ${ }^{22,54}$ This exaggerated hemodynamic response often results in pulmonary edema, myocardial dysfunction, and intracranial hypertension. ${ }^{54-57}$ For these reasons, we believe that to obtain the highest possible benefit from this intervention, the clinical response to resuscitation should be evaluated continuously, to best estimate when the balloon should be moved from zone 1 to 3 , without conducting a higher risk of complications due to ischemia and reperfusion injury. The decision to place a REBOA at zone 1 or 3 depends on the injury pattern and physiologic devastation of the patient, with the understanding that occlusion at zone 1 carries significant consequence and should only be performed when risks exceed potential benefits and the duration of which can be limited. Indiscriminate use of REBOA at zone 1 should be avoided.

- Step 3-Balloon Inflation: Once the balloon is confirmed to be in the proper location, it must be manually inflated until the aortic flow is halted. Over-inflation of the balloon may lead to artery or balloon rupture. In addition, over-inflation can lead to aortic overpressure injury, creating an arterial dissection or 


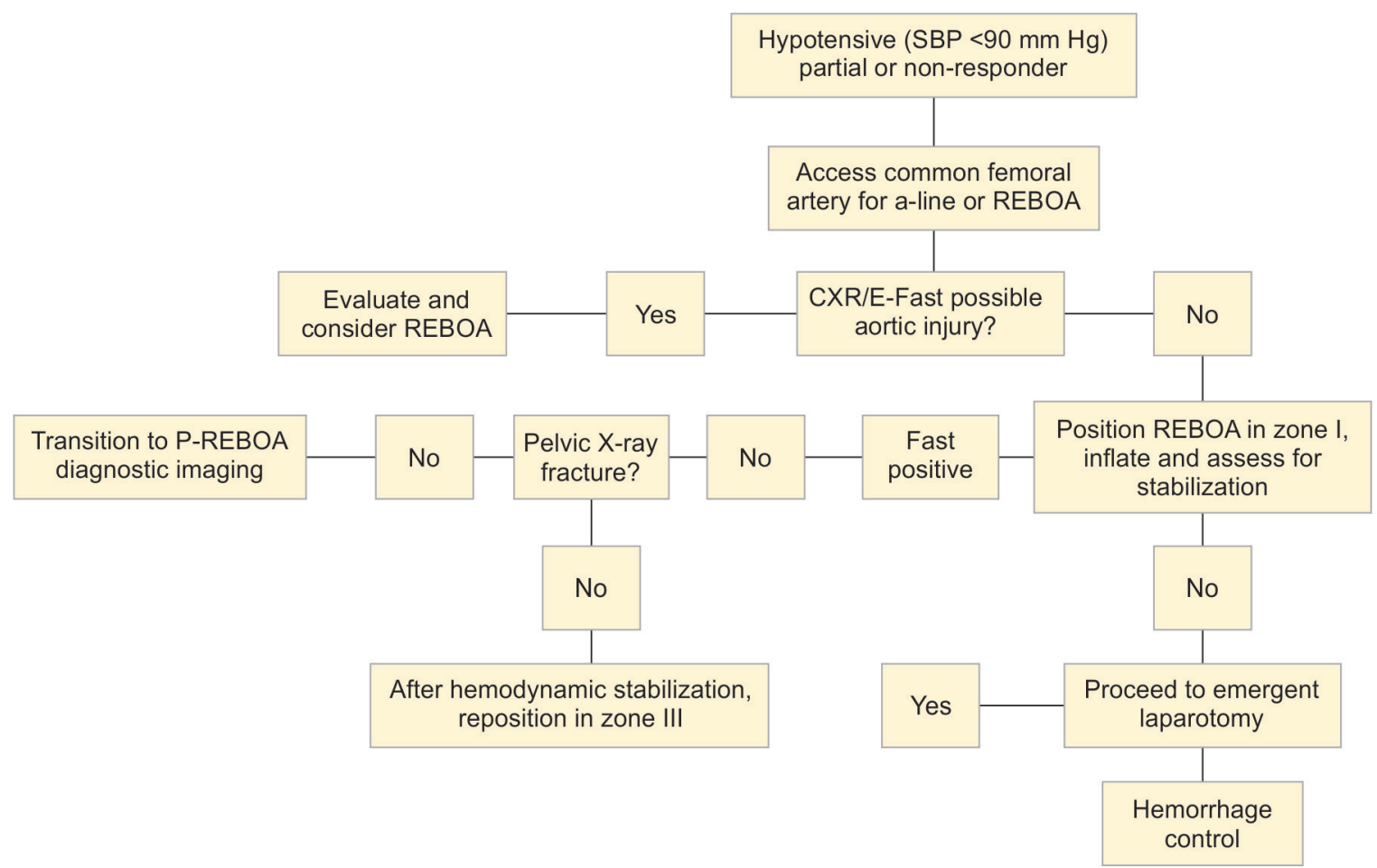

Fig. 2: A proposal for pelvic trauma management with REBOA: Latinamerican perspective

intimal injury that can lead to long-term vascular complications. ${ }^{58}$ In the absence of imaging, a distal arterial waveform may be measured from the insertion sheath. ${ }^{59}$ If present prior to balloon inflation, the waveform will disappear upon complete aortic occlusion. However, severe vasospasm or limited flow between the sheath and catheter may preclude the measurement of a distal arterial waveform. ${ }^{60}$ Therefore, some providers recommend using either a slightly larger sheath or an additional contralateral sheath to improve distal hemodynamic monitoring. Similarly, Doppler ultrasound of the contralateral femoral artery may be used to confirm aortic occlusion. In the absence of these adjunctive measures, the return of radial pulses and the loss of previously present femoral pulses bilaterally can also be used to confirm adequate inflation. Similarly, the loss of a single femoral pulse indicates iliac placement. If fluoroscopy or X-ray is available, we recommend inflating the balloon with a mix of saline and contrast to facilitate the visualization of the balloon.

- Step 4-Management During Balloon Occlusion: One area of consensus is that the ischemic burden due to REBOA increases as occlusion time increases. The cessation of distal blood flow results in distal organ ischemia, vasodilation, and a buildup of toxic metabolites. ${ }^{6,61,62}$ Mechanisms to reduce occlusion time and restore distal perfusion include intermittent REBOA, partial REBOA, and repositioning the catheter to more distal levels of occlusion. Alternative resuscitation strategies including selective delivery of products to the proximal or distal circulation, novel automated aortic control devices, and REBOA combined with arterial bypass are being developed to further extend the tolerable duration of ischemia but have not yet been widely used clinically. ${ }^{63,64}$

- Step 5-Balloon Deflation: Slow, methodical balloon deflation is generally advised, as abrupt loss of aortic afterload results in reallocation of circulating blood volume to a much larger volume of distribution. The combined effect is profound vasodilation and a bolus of ischemic metabolites returning to systemic circulation that may lead to cardiovascular collapse. ${ }^{48,65}$ Current guidelines advocated in the Basic Endovascular Skills for Trauma ${ }^{\mathrm{TM}}$ Course recommend slow, graded balloon deflation over a period of at least 5 minutes, as this is analogous to removing an aortic cross-clamp during open surgery. ${ }^{41}$ Communication between the surgeon and the anesthesiologist is essential to time the delivery of blood products and adjunctive medications as the balloon is deflated. Some authors use vasoactive medications as a bridge for blood pressure support following balloon deflation and utilize end-tidal $\mathrm{CO}_{2}$ to guide reperfusion. Calcium administration may mitigate the cardiac effects of hyperkalemia and counteract citrate from blood product administration. The balloon should be deflated as slowly as possible. If distal arterial monitoring is available, an increase in distal pressure and the emergence of a pulsatile waveform are the first indicators that aortic flow is beginning to return. ${ }^{65,66}$ The balloon may be deflated rapidly until the distal 
Table 1: The REBOA open gap from trauma surgeons from the Americas

Really, continue REBOA being an absolute contraindication in thoracic injuries?

In pelvic trauma, is there a greater benefit if the user is first in Zone I and then in Zone III?

Could be the clinical evaluation validated as a definitive method for checking the proper positioning of the balloon?

Is it possible to get arterial access by cut-down puncturing the 1 common femoral artery without needing to dissect it? What is the best protocol for clinical monitoring after removing the catheter?

What are the patients who really benefit from post-REBOA heparinization?

Should REBOA replace $\mathrm{RT}$ in the setting of blunt trauma arrest?

Could REBOA offer benefits for non-trauma patients in cardiac arrest?

Are there another patients with exsanguinating hemorrhage (non, trauma) that are candidates for management with REBOA?

waveform returns, at which point the rate should significantly decrease. If arterial blood pressure drops significantly, volume should be added to the balloon. If the patient becomes unstable, re-inflation of the balloon may be required.

- Step 6-Sheath Removal and Post-resuscitation Care: Continuous arterial Doppler and frequent compartment pressure monitoring have been suggested as adjuncts after REBOA removal, particularly in patients with concomitant extremity injury. However, the presence of audible Doppler signals distally does not preclude partial thrombosis or compartment syndrome. Whereas systemic heparin is often contraindicated in trauma patients, intermittent heparin flushing or continuous low-dose heparin infusion via indwelling arterial sheaths has been utilized to decrease sheath related thrombosis in other populations. ${ }^{67-69}$ However, this routine practice remains controversial in the trauma patient (Table 1). Where and when to remove the sheath depends on the coagulation profile of the patient, the perfusion status of the ipsilateral extremity, and the overall physiology of the patient. Complications such as thrombus in the sheath, distal thrombosis, and ischemia, difficulty with removal of the in-dwelling devices should prompt consultation with interventional colleagues. Once the sheath is removed, a duplex should be performed within 24 to 72 hours to exclude access site complications.

\section{CONCLUSION}

The REBOA is a novel tool and an adjunct to modern-day damage control resuscitation which aims in achieving hemorrhage control in hemodynamically unstable patients. Its role and impact on the survival of trauma patients compared with conventional techniques such as resuscitative thoracotomy remain controversial, and evidence from controlled clinical trials is necessary to support these assumptions. However, the experiences reported by high-volume trauma centers show that it has a promising future and that it is feasible to use in other dire scenarios other than trauma.

Its use by trauma and acute care surgeons in North America dates back 5 years, in the rest of the Americas it is a tool that has been used more and more frequently every day. Although indications for its management have been established, there are still questions about it that have not been clarified. Therefore, we must continuously work on evaluating the existing evidence as well as building and collecting new data, with the aim of making this intervention a tool that potentially improves the overall survival of all our patients.

\section{REFERENCES}

1. Saito N, Matsumoto H, Yagi T, Hara Y, Hayashida K, Motomura $\mathrm{T}$, et al. Evaluation of the safety and feasibility of resuscitative endovascular balloon occlusion of the aorta. J Trauma Acute Care Surg. 2015;78(5):897-904.

2. Kisat M, Morrison JJ, Hashmi ZG, Efron DT, Rasmussen TE, Haider AH. Epidemiology and outcomes of non-compressible torso hemorrhage. J Surg Res [Internet]. Elsevier Inc; 2013;184(1):414-421.

3. Feng CYD, Reis R, Rodrigues VC, Renata L. Oclusão ressuscitativa por meio de balão endovascular da aorta (REBOA): revisão atualizada . 2018;45(1):1-9.

4. Hughes CW. Use of an intra-aortic balloon catheter tamponade for controlling intra-abdominal hemorrhage in man. Surgery [Internet]. 1954 Jul [cited 2018 Jul 3];36(1):65-68.

5. Ledgerwood AM, Kazmers M, Lucas CE. The role of thoracic aortic occlusion for massive hemoperitoneum. J Trauma [Internet]. 1976 Aug [cited 2018 Jul 3];16(08):610-615.

6. Avaro J-P, Mardelle V, Roch A, Gil C, de Biasi C, Oliver M, et al. Forty-minute endovascular aortic occlusion increases survival in an experimental model of uncontrolled hemorrhagic shock caused by abdominal trauma. J Trauma [Internet]. 2011 Sep [cited 2018 Jul 3];71(3):720-5; discussion 725-726.

7. Stannard A, Eliason JL, Rasmussen TE. Resuscitative endovascular balloon occlusion of the aorta (REBOA) as an adjunct for hemorrhagic shock. J Trauma [Internet]. 2011 Dec [cited 2018 Jun 29];71(6):1869-1872.

8. Davidson AJ, Russo RM, Reva VA, Brenner ML, Moore LJ, Ball C, et al. The pitfalls of resuscitative endovascular balloon occlusion of the aorta. J Trauma Acute Care Surg [Internet]. 2018 Jan 4 [cited 2018 Jul 6];84(1):192-202.

9. Manzano-Nunez R, Orlas CP, Herrera-Escobar JP, Galvagno S, DuBose J, Melendez JJ, et al. A meta-analysis of the incidence of complications associated with groin access after the use of resuscitative endovascular balloon occlusion of the aorta in trauma patients [Internet]. Vol. Publish Ah, Journal of Trauma and Acute Care Surgery. 9000.

10. Ordoñez CA, Parra MW, Manzano-Nunez R, Herrera-Escobar JP, Serna JJ, Rodriguez Ossa P, et al. Intraoperative combination of resuscitative endovascular balloon occlusion of the aorta and a median sternotomy in hemodynamically unstable 
patients with penetrating chest trauma: Is this feasible? J Trauma Acute Care Surg. 2018;84(5):752-757.

11. Biffl WL, Fox CJ, Moore EE. The role of REBOA in the control of exsanguinating torso hemorrhage. J Trauma Acute Care Surg. 2015;78(5):1054-1058.

12. Burlew CC, Moore EE, Moore FA, Coimbra R, McIntyre RC, Davis JW, et al. Western Trauma Association critical decisions in trauma: resuscitative thoracotomy. J Trauma Acute Care Surg [Internet]. 2012 Dec [cited 2018 Jul 6];73(6):1359-1363.

13. Brenner M, Teeter W, Hoehn M, Pasley J, Hu P, Yang S, et al. Use of Resuscitative Endovascular Balloon Occlusion of the Aorta for Proximal Aortic Control in Patients With Severe Hemorrhage and Arrest. JAMA Surg [Internet]. 2018 Feb 1 [cited 2018 Jun 29];153(2):130-135.

14. Teeter W, Romagnoli A, Wasicek P, Hu P, Yang S, Stein D, et al. Resuscitative Endovascular Balloon Occlusion of the Aorta Improves Cardiac Compression Fraction Versus Resuscitative Thoracotomy in Patients in Traumatic Arrest. Ann Emerg Med [Internet]. 2018 Oct [cited 2018 Nov 22];72(4):354-360.

15. Teeter W, Bradley M, Romagnoli A, Hu P, Li Y, Stein D, Scalea T BM. Treatment effect or effective treatment? Total Cardiac Compression Fraction and End Tidal $\mathrm{CO}_{2}$ is higher in patients receiving REBOA compared to RT. Press Am Surg.

16. Bradley MJ, Bonds BW, Chang L, Yang S, Hu P, Li H-C, et al. Open chest cardiac massage offers no benefit over closed chest compressions in patients with traumatic cardiac arrest. J Trauma Acute Care Surg [Internet]. 2016 Nov [cited 2018 Dec 8];81(5):849-854.

17. Brenner M, Bulger EM, Perina DG, Henry S, Kang CS, Rotondo $\mathrm{MF}$, et al. Joint statement from the American College of Surgeons Committee on Trauma (ACS COT) and the American College of Emergency Physicians (ACEP) regarding the clinical use of Resuscitative Endovascular Balloon Occlusion of the Aorta (REBOA). Trauma Surg Acute Care Open [Internet]. 2018;3(1):e000154.

18. Berg RJ, Inaba K, Okoye O, Karamanos E, Strumwasser A, Chouliaras $\mathrm{K}$, et al. The peril of thoracoabdominal firearm trauma: 984 civilian injuries reviewed. J Trauma Acute Care Surg [Internet]. 2014 Nov [cited 2018 Jul 6];77(5):684-691.

19. Resuscitative Endovascular Balloon Occlusion of the Aorta (REBOA) for Hemorrhagic Shock (CPG ID: 38). [cited 2018 Jul 6].

20. Van Harreveld A, Feigen Ga, Lerman LS. Hemodynamics of aortic occlusion. Am J Physiol [Internet]. 1949 Apr [cited 2018 Jul 10];157(1):168-176.

21. Dunn EL, Moore EE, Moore JB. Hemodynamic effects of aortic occlusion during hemorrhagic shock. Ann Emerg Med [Internet]. Mosby; 1982 May 1 [cited 2018 Jul 10];11(5):238-241.

22. Stokland O, Miller MM, Ilebekk A, Kiil F. Mechanism of hemodynamic responses to occlusion of the descending thoracic aorta. Am J Physiol Circ Physiol [Internet]. 1980 Apr [cited 2018 Jul 10];238(4):H423-429.

23. DuBose JJ, Scalea TM, Brenner M, Skiada D, Inaba K, Cannon J, et al. The AAST prospective Aortic Occlusion for Resuscitation in Trauma and Acute Care Surgery (AORTA) registry: Data on contemporary utilization and outcomes of aortic occlusion and resuscitative balloon occlusion of the aorta (REBOA). J Trauma Acute Care Surg [Internet]. 2016 Sep [cited 2018 Dec 8];81(3):409-419.

24. Romagnoli A, Teeter W, Pasley J, Hu P, Hoehn M, Stein D, et al. Time to aortic occlusion: It's all about access. J Trauma Acute Care Surg [Internet]. 2017 Dec [cited 2018 Dec 8];83(6):1161-1164.
25. Ordoñez CA, Manzano-Nunez R, Parra MW, Rasmussen TE, Nieto AJ, Herrera-Escobar JP, et al. Prophylactic use of resuscitative endovascular balloon occlusion of the aorta in women with abnormal placentation: A systematic review, meta-analysis, and case series. J Trauma Acute Care Surg. 2018;84(5):809-818.

26. Biffl WL, Smith WR, Moore EE, Gonzalez RJ, Morgan SJ, Hennessey T, et al. Evolution of a multidisciplinary clinical pathway for the management of unstable patients with pelvic fractures. Ann Surg [Internet]. 2001 Jun [cited 2018 Jul 10];233(6):843-850.

27. Burlew CC, Moore EE, Smith WR, Johnson JL, Biffl WL, Barnett CC, et al. Preperitoneal Pelvic Packing/External Fixation with Secondary Angioembolization: Optimal Care for Life-Threatening Hemorrhage from Unstable Pelvic Fractures. J Am Coll Surg [Internet]. 2011 Apr [cited 2018 Jul 10];212(4):628-635.

28. Martinelli T, Thony F, Decléty P, Sengel C, Broux C, Tonetti J, et al. Intra-Aortic Balloon Occlusion to Salvage Patients With Life-Threatening Hemorrhagic Shocks From Pelvic Fractures. J Trauma Inj Infect Crit Care [Internet]. 2010 Feb [cited 2018 Jul 10;68(4):1.

29. Shrivastava V, Nageotte M, Major C, Haydon M, Wing D. Case-control comparison of cesarean hysterectomy with and without prophylactic placement of intravascular balloon catheters for placenta accreta. Am J Obstet Gynecol [Internet]. 2007 Oct [cited 2018 Jul 10];197(4):402.e1-402.e5.

30. Salim R, Chulski A, Romano S, Garmi G, Rudin M, Shalev E. Precesarean Prophylactic Balloon Catheters for Suspected Placenta Accreta: A Randomized Controlled Trial. Obstet Gynecol [Internet]. 2015 Nov [cited 2018 Jul 10];126(5):1022-1028.

31. Wu Q, Liu Z, Zhao X, Liu C, Wang Y, Chu Q, et al. Outcome of Pregnancies After Balloon Occlusion of the Infrarenal Abdominal Aorta During Caesarean in 230 Patients With Placenta Praevia Accreta. Cardiovasc Intervent Radiol [Internet]. Springer US; 2016 Nov 20 [cited 2018 Jul 10];39(11):1573-1579.

32. Panici PB, Anceschi M, Borgia ML, Bresadola L, Masselli G, Parasassi T, et al. Intraoperative aorta balloon occlusion: fertility preservation in patients with placenta previa accreta/ increta. J Matern Neonatal Med [Internet]. 2012 Dec 20 [cited 2018 Jul 10];25(12):2512-2516.

33. Ballas J, Hull AD, Saenz C, Warshak CR, Roberts AC, Resnik $R R$, et al. Preoperative intravascular balloon catheters and surgical outcomes in pregnancies complicated by placenta accreta: a management paradox. Am J Obstet Gynecol [Internet]. 2012 Sep [cited 2018 Jul 10];207(3):216.e1-216.e5.

34. Guerrier G, Oluyide B, Keramarou M, Grais R. High maternal and neonatal mortality rates in northern Nigeria: an 8-month observational study. Int J Womens Health [Internet]. Dove Press; 2013 [cited 2018 Jul 10];5:495-499.

35. Hoehn MR, Hansraj NZ, Pasley AM, Brenner M, Cox SR, Pasley JD, et al. Resuscitative endovascular balloon occlusion of the aorta for non-traumatic intra-abdominal hemorrhage. Eur J Trauma Emerg Surg [Internet]. 2018 Jun 19 [cited 2018 Oct 31].

36. Goodenough CJ, Cobb TA, Holcomb JB. Use of REBOA to stabilize in-hospital iatrogenic intra-abdominal hemorrhage. Trauma Surg acute care open [Internet]. 2018 Oct 1 [cited 2018 Dec 8;3(1):e000165].

37. Doucet J, Coimbra R. REBOA: is it ready for prime time? J Vasc Bras [Internet]. 2017 Mar [cited 2018 Jul 10];16(1):1-3 
38. Manley JD, Mitchell BJ, DuBose JJ, Rasmussen TE. A Modern Case Series of Resuscitative Endovascular Balloon Occlusion of the Aorta (REBOA) in an Out-of-Hospital, Combat Casualty Care Setting. J Spec Oper Med [Internet]. [cited 2018 Jul 10];17(1):1-8.

39. Wasicek PJ, Teeter WA, Yang S, Hu P,Hoehn MR, Stein DM, etal. Life over Limb: Lower Extremity Ischemia in the Setting of Resuscitative Endovascular Balloon Occlusion of the Aorta (REBOA). Am Surg [Internet]. 2018 Jun 1 [cited 2018 Dec 8];84(6):971-977.

40. Stannard A, Eliason JL, Rasmussen TE. Resuscitative endovascular balloon occlusion of the aorta (REBOA) as an adjunct for hemorrhagic shock. J Trauma - Inj Infect Crit Care. 2011;71(6):1869-1872.

41. Brenner M, Hoehn M, Pasley J, Dubose J, Stein D, Scalea T. Basic endovascular skills for trauma course. J Trauma Acute Care Surg [Internet]. 2014 Aug [cited 2018 Jul 11];77(2):286-291.

42. Villamaria CY, Eliason JL, Napolitano LM, Stansfield RB, Spencer JR, Rasmussen TE. Endovascular Skills for Trauma and Resuscitative Surgery (ESTARS) course. J Trauma Acute Care Surg [Internet]. 2014 Apr [cited 2018 Jul 11];76(4):929-936.

43. Hilty WM, Hudson PA, Levitt MA, Hall JB. Real-time ultrasound-guided femoral vein catheterization during cardiopulmonary resuscitation. Ann Emerg Med [Internet]. 1997 Mar [cited 2018 Jul 12];29(3):331-6; discussion 337.

44. Arthurs Z, Starnes B, See C, Andersen C. Clamp Before You Cut: Proximal Control of Ruptured Abdominal Aortic Aneurysms Using Endovascular Balloon Occlusion. Vasc Endovascular Surg [Internet]. 2006 Mar 19 [cited 2018 Jul 12];40(2):149-155.

45. Hörer TM, Skoog P, Pirouzram A, Nilsson KF, Larzon T. A small case series of aortic balloon occlusion in trauma: lessons learned from its use in ruptured abdominal aortic aneurysms and a brief review. Eur J Trauma Emerg Surg [Internet]. 2016 Oct 28 [cited 2018 Jul 12];42(5):585-592.

46. Wasicek PJ, Shanmuganathan K, Teeter WA, Gamble WB, Hu P, Stein DM, et al. Assessment of Blood Flow Patterns Distal to Aortic Occlusion Using CT in Patients with Resuscitative Endovascular Balloon Occlusion of the Aorta. J Am Coll Surg [Internet]. 2018 Mar [cited 2018 Dec 8];226(3):294-308.

47. Brenner ML, Moore LJ, DuBose JJ, Tyson GH, McNutt MK, Albarado RP, et al. A clinical series of resuscitative endovascular balloon occlusion of the aorta for hemorrhage control and resuscitation. J Trauma Acute Care Surg [Internet]. 2013 Sep [cited 2018 Jul 12];75(3):506-511.

48. Gelman S. The pathophysiology of aortic cross-clamping and unclamping. Anesthesiology [Internet]. 1995 Apr [cited 2018 Jul 12];82(4):1026-1060.

49. D'Ambra MN, Dewhirst W, Jacobs M, Bergus B, Borges L, Hilgenberg A. Cross-clamping the thoracic aorta. Effect on intracranial pressure. Circulation [Internet]. 1988 Nov [cited 2018 Jul 12];78(5 Pt 2):III198-202.

50. Moore LJ, Brenner M, Kozar RA, Pasley J, Wade CE, Baraniuk MS, et al. Implementation of resuscitative endovascular balloon occlusion of the aorta as an alternative to resuscitative thoracotomy for noncompressible truncal hemorrhage. J Trauma Acute Care Surg [Internet]. 2015 Oct [cited 2018 Jul 12];79(4):523-532.

51. Morrison JJ, Percival TJ, Markov NP, Villamaria C, Scott DJ, Saches KA, et al. Aortic balloon occlusion is effective in controlling pelvic hemorrhage. J Surg Res [Internet]. 2012 Oct [cited 2018 Jul 12];177(2):341-347.
52. Martinelli T, Thony F, Decléty P, Sengel C, Broux C, Tonetti J, et al. Intra-Aortic Balloon Occlusion to Salvage Patients With Life-Threatening Hemorrhagic Shocks From Pelvic Fractures. J Trauma Inj Infect Crit Care [Internet]. 2010 Feb [cited 2018 Jul 12];68(4):1.

53. Tibbits EM, Hoareau GL, Simon MA, Davidson AJ, DeSoucy ES, Faulconer ER, et al. Location Is Everything. J Trauma Acute Care Surg [Internet]. 2018 Feb [cited 2018 Jul 12];1.

54. Dunn E, Prager RL, Fry W, Kirsh MM. The effect of abdominal aortic cross-clamping on myocardial function. J Surg Res [Internet]. 1977 May [cited 2018 Jul 12];22(5):463-468.

55. Morrison JJ, Ross JD, Markov NP, Scott DJ, Spencer JR, Rasmussen TE. The inflammatory sequelae of aortic balloon occlusion in hemorrhagic shock. J Surg Res [Internet]. 2014 Oct [cited 2018 Jul 12];191(2):423-431.

56. Fuller G, Hasler RM, Mealing N, Lawrence T, Woodford M, Juni $\mathrm{P}$, et al. The association between admission systolic blood pressure and mortality in significant traumatic brain injury: A multi-centre cohort study. Injury [Internet]. 2014 Mar [cited 2018 Jul 12];45(3):612-617.

57. Kralovich KA, Morris DC, Dereczyk BE, Simonetti V, Williams M, Rivers EP, et al. Hemodynamic effects of aortic occlusion during hemorrhagic shock and cardiac arrest. J Trauma [Internet]. 1997 Jun [cited 2018 Jul 12];42(6):1023-1028.

58. Wasicek PJ, Teeter WA, Brenner ML, Hoehn MR, Scalea TM, Morrison JJ. Resuscitative endovascular balloon occlusion of the aorta: rupture risk and implications for blind inflation. Trauma Surg acute care open [Internet]. 2018 Jan 24 [cited 2018 Dec 8];3(1):e000141.

59. Johnson MA, Neff LP, Williams TK, DuBose JJ, EVAC Study Group. Partial resuscitative balloon occlusion of the aorta (P-REBOA). J Trauma Acute Care Surg [Internet]. 2016 Nov [cited 2018 Jul 12];81(5 Suppl 2 Proceedings of the 2015 Military Health System Research Symposium):S133-7.

60. DuBose JJ. How I do it. J Trauma Acute Care Surg [Internet]. 2017 Jul [cited 2018 Jul 12];83(1):197-199.

61. Hörer TM, Skoog P, Nilsson KF, Oikonomakis I, Larzon T, Norgren L, et al. Intraperitoneal Metabolic Consequences of Supraceliac Aortic Balloon Occlusion in an Experimental Animal Study Using Microdialysis. Ann Vasc Surg [Internet]. 2014 Jul [cited 2018 Jul 12];28(5):1286-1295.

62. Reva VA, Matsumura Y, Hörer T, Sveklov DA, Denisov A V., Telickiy SY, et al. Resuscitative endovascular balloon occlusion of the aorta: what is the optimum occlusion time in an ovine model of hemorrhagic shock? Eur J Trauma Emerg Surg [Internet]. 2016 Oct 13 [cited 2018 Jul 12].

63. Manning JE, Ross JD, McCurdy SL, True NA. Aortic Hemostasis and Resuscitation: Preliminary Experiments Using Selective Aortic Arch Perfusion With Oxygenated Blood and Intra-aortic Calcium Coadministration in a Model of Hemorrhage-induced Traumatic Cardiac Arrest. Olson JE, editor. Acad Emerg Med [Internet]. 2016 Feb [cited 2018 Jul 12];23(2):208-12.

64. Williams TK, Neff LP, Johnson MA, Ferencz S-A, Davidson AJ, Russo RM, et al. Extending resuscitative endovascular balloon occlusion of the aorta. J Trauma Acute Care Surg [Internet]. 2016 Aug [cited 2018 Jul 12];81(2):294-301.

65. Johnson MA, Davidson AJ, Russo RM, Ferencz S-AE, Gotlib O, Rasmussen TE, et al. Small changes, big effects. J Trauma Acute Care Surg [Internet]. 2017 Jun [cited 2018 Jul 12];82(6):1106-1111

66. Davidson AJ, Russo RM, Ferencz S-AE, Cannon JW, Rasmussen TE, Neff LP, et al. Incremental balloon deflation following 
complete resuscitative endovascular balloon occlusion of the aorta results in steep inflection of flow and rapid reperfusion in a large animal model of hemorrhagic shock. J Trauma Acute Care Surg [Internet]. 2017 Jul [cited 2018 Jul 12];83(1):139-143.

67. Koenigsberg RA, Wysoki M, Weiss J, Faro SH, Tsai FY. Risk of Clot Formation in Femoral Arterial Sheaths Maintained Overnight for Neuroangiographic Procedures. AJNR Am J Neuroradiol [Internet]. 1999 [cited 2018 Jul 12];20:297-299.
68. Benson LM, Wunderly D, Perry B, Kabboord J, Wenk T, Birdsall B, et al. Determining best practice: Comparison of three methods of femoral sheath removal after cardiac interventional procedures. Hear Lung J Acute Crit Care [Internet]. 2005 Mar [cited 2018 Jul 12];34(2):115-121.

69. Brenner M, Hoehn M, Pasley J, Dubose J, Stein D, Scalea T. Basic endovascular skills for trauma course. J Trauma Acute Care Surg [Internet]. 2014 Aug [cited 2018 Jul 12;77(2): 286-291. 